\title{
LIST SWIETEGO AUGUSTYNA DO POGAN W MADAURZE
}

\section{Tæo 1 czas napisania listu}

Zarówno tło, Jak 1 czas napisanla l1stu poznajery z jego treśc1. Z 11stu św. Augustyna do członków rady miejsisioj /ordo/ w Madaurze ${ }^{1}$ wynika, ze otrzymał od nich pisino, w którym prosill go, aby zaJłł się Jednym $z$ ich współobywatel1. Biskup spełnił ich życzenie, Jak to wynika z jego wypowiedzi:

\footnotetext{
"quantum potul quiden in negotio fratris Florent, per quem

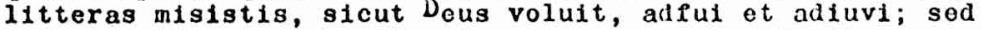
tale nogotium orat, quod etian sine opera mea facile peragi posset; prope omnes enim domus 1psius homines, qui apud IIfpponom sunt, noverunt Florentium et multum eius orbitatem dolont"2.
}

Lac1ŕsk1 termin "orb1tas" wskazuje na utratę dzicci, ispółmałzonka, rodziców albo innych dóbr. Z listu jednak nie wiadomo, o co dokładnie chodziło. Augustyn udzteliz ponocy Florencjuszori, chociaz 1 bez jego wsparola uczyniliby to współczujł̨cy mu mieszkańcy okol1c IIfppony.

Trudno jest ustallé czas tej korespondencjl. Biskup w swyin lisc1e stwierdza, żo świątynie bogów pogańsistch są zniszczono: częściowo zrujnowane, a częściowo zanknięte lub wykorzystane na śwleok1 użytek, obrazy bogów rozbite lub spalone. Chrześcijanie, którzy przedtem byl1 prześladowani pazez wadze państwowa, zwycį̧zyli ja nie sprzeciwem, lecz przyjłclem śmiorci. Moc prawa zmieniono przeciwko tym obrazom, z powodu których poprzednlo mordowano chrześcijan. Sam

1 Eplstola 232, CSEL 57,511-518, PL 33,1025-1029. Madaura była mlastem polożonym Numid11, gdzie św.Augustyn ukoniczył studia gramatyczne. Por. Confessiones II, 3,5, CSSEL 33,32.

2 Epistola 232,7, CSEL 57,516. 
cosarz opromienionego sławz paistwa modly sie pokornie przy grobie Plotra rybaka ${ }^{3}$.

Augustyn wskazuje ponasto na wazne, czesto nie dostrzegane, przeciwienstwa. Bdykty dawnych cesarzy kierowane przeciw chrześc1janom żzdaxy zaparcia sie wiary, czego znakien było sprawowanie kultu pogańskiego. Cesarze chrześcijańcy prześladowali 1 gnęull ten kult, ale pozwalali na pewne jego przejawy w sposób dopuszczalny przez prawo. Przylus nawróceń ze strony państwa nie był stosowany. Poganie mogll korzystać ze swoich praw obywatelskich nawet za rziłuów Honorłusza. Z wyjttkiem najwyższych urzęów dworsk1ch, zachowal1 dostep do wszystafch funkcji paústwowycil. prawo chroniło ich przed swawola 1 niesprawiedliwościa ze strony chrześcijan ${ }^{4}$. Według Augusty-

3 Tamże 3, CSbL 57,513;W r. 399 wodzowie cesarza Ionor1usza, Gaudencjusz i Jowtusz zniszczyli 1 zamknęli wiele świztyí w Apryco Północnej. Por. De civitate Dei XVIII, 54, CC 48,655, Quodvultalous, Libor de promissionibus $3,38,41$, SCh 102,568 nn. Augustyn w Contra Listolam Parmeniani $1,9,15$, PL $43,44-45$ czyni aluzje do praw z dnia 21.I. 120 .VIII. 399 r. Por. Codex Thoodosianus $16,10,15$, 17. Prawo o usuni zeciu posaggów pogańskich ze śwlątyń wydano 15.XI. $407 \mathrm{r}$. Por. Codex Theodosianus 16,10,19. Dokładniej zagadnienie to omawiaja $\vec{F}$. Van Der Meor, Augustino the Bishop/z Jezyka niderlandzkiefo przełozyli: B. Battershaw $1 \mathrm{G}$.Lanb/, Lond on 1969, 37-40 oraz 0.Perlor, Les voyages de Saint Augustin, Paris 1969, 391-395. Por. także I'.Kotula, A I'l'ka Północna w starożytności, Wrocław 1972,232 oraz C.Lepelly, Les cités de l'Afrique konaine au Bas Empire, Paris 1979, t.1, 355.

* Honoriusz na jakiś czas odstapił od zasady Teodozjusza Wielkiego, który przy angazowaniu do słuzby państwowej nio uwgględniat wyznania, ponjewaz w $408 \mathrm{r}$. wyłtezy pogan wraz z heretykami od najwyższych urzęów dworskich. Por. Codex Thoodosianus, De haereticis 16,5,42: "Los qui catholicae sectae sunt inimic1, 1ntra palatium inilitare prohibemus". Powoden ogłoszenia tego prawa stało 51 g podejrzenie podntesione przectw Stylichonowi dowodzace, ze d tży on do korony dla swego syna Eucherlusza wychowanogo w werze pograliskiej. Larówno to prawo wydane przez Lonoriusza,jak 1 prawo

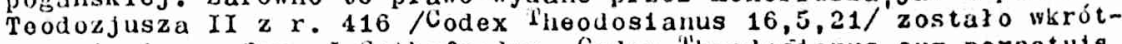
co zndesione. Por. J.Gothofredus, Codex 'iheodosianus cum perpetuis commentar11s, Lipslae 1736,43. W r. 423 zo wzgledu na pewne nadużc1a zo strony cirzescijan, Teodozjusz II wziłz w oploke prawa $\angle y-$ dów 1 pogan/Codex Iustinianus 1,11,6/: "Christianis, qui vel vere ount vel esse dicuntur, specialiter domandamus, ut Iudaels ac paganis in quioto degentibus nihilque teaptantibus turbulentum legibusque contrarium non audeant manus inferre religionis auctoritato abusi. Nam si contra securos fuorint violonti vel oorum bona diripuerint, non ea sola quas abstulerint, sod nonvicti in duplum quae rapuerint restituere compellantur. lioctores ot law provinciarum et officia et principalos cognosoant se, si non 1 psi 
na bardzo wielu zwracało sle ku chrześcijaństwu wskutek istniejących praw, 1 poganio,w porównantu z chrześcijanam1, stanowili w tym czasie w Afryce Póznocnej wyraźna mniejszośc ${ }^{5}$. Pomimo to tworzyli wcilz potezno 1 wpływowe stronnictwo. Pogaúska rada miejska byza jeszcze czynna w diadaurzo. B1skup mów téz o wielu, którzy byl1: "praecisi a radice Christianae societatis"6. Wydaje s1e, ze mial tu na myśli donatystów. Wszystk1e dane mynikające z listu odnoszą sie do sytuacji, jaka panorała $w$ Afryce Północnej w plerwszym dz1esię$01010 c 1 u \mathrm{~V}$ wieku. W tym czasie musiała zatem nastąpló wymiana listów mizdzy blskupem lilppony a członkami rady miejskiej w Madaurze. Pogaństwo weryce tkw1ło przode wszystkim w wyżsych warstwach społeczenstwa, w kregach znakoritych obywateli 1 intelektualistów. Przywízanio do religli tradycyjnej w klasie rzadzącej w mlastach afrykaiskioh było śc1śle spokrownione z tym, co panowarow senacie rzymskim w kregu Symmacha ${ }^{7}$. Trudno z cała pewnościa stwlerdzló czy duchownl otoczyli tę warstwe społeczeństwa szczególna troską duszpasterską. Mozna jednak sądzió, ze nie byll w stosunku do nich obojetni. Opór wykształconych pogan był jednak silniejszy. Mial on rózne źródła. Przede wszystkim trzeba wymienić kapłanów sprawujących kult dawnej religil 1 stanowiacych podporę zanikajucego pogaústwa ${ }^{8}$. Nalezy tez wyszczególnió pogląd na śwat, który ozywial tych ludzl. Poprzestawali oni na swojej filozofil.

talla vindicent, sed fieri a popularibus hoc permiserint, ut eos qui fecerint puntendos". Por. B.Kumor, Historia Kościoła, cz.1. Starozytność chrześc1jańska, Lublin 1973, 143.

5 Eplstola 97,4 /Ad Ulymplum/, CSLL 34,519: "Multum sane de quorundam noque paucorum fide firma et stabili gratulamur, qui ex occasiono legui lpsarum ad Christianam religionem vel catholican pacer conversi sunt, pro quorum salute sempiterna nos in hac temporali etiam periciltari delectat".

6 Epistola 232,3, CSLL 57,513: "Videtis certe multos praecisos a radice Cliristianae societatis, quae per scies apostolorum et successiones episcoporum certa per orben propagatione diffunditur, de sola figura originis sub christiano nomine quasi arescontia sarmenta gloriari quas huereses ot schismata nominaras".

7 C.lepelloy, dzecyt. 358; P.Brown, Aspects of the Christianisation of the lioman iristocracy, w: lieligion and Society in tho Ago of Saint Augustine, Now York 1973, 161-182.

8 Panistwo w r. 415 wystapplo przeclw intrygom kapłanów poganiskich wobec Kościola. Por. Codex Thoodosianus 16,10,20. 
Zapowne wielkiz role odgrywał takze pierwiastek czysto ludzk1. Interesy pienięźno byly bowloin zagrożone przez nowa religie. Nie trudno równieź dostrzec, że wraz z rozwojen potęi Kościoła zmniejezało się znaczenie 1 wpływ dotychczasowych warstw panujących. lizłazazcy poganie dostrzegal1, zo wzrastała władza b1skupów, podczas gdy ich własna naliła. Nie mogło to więc pozostaó bez znaczenta. Vla pogańskich mieszkańców Madaury nie było rzecza łatwa zwróció się $z$ prośba do biskupa llippony, choć zdawali sobie sprawe z togo,

iz ten człowiok znaczył więcej niz onl. W tym wyrazaza sie ta wielka przeniana epoki, która mogła wywołać u pogan gorzkio uczuc1a w stosunku do chrześoljan. W zwizzku z tym mozna przypuszczać, zo wykształcent poganie nie byll zbyt silnie przywiazani do dawnego kultu, alo od wstąpienta do Kościoła powstrzymywała $1 \mathrm{ch}$ wasna pycha. Augustyn nie bez powodu tnów1 w swym liście o pysze 1 pokorze, bowiom nauke chrześcijaúska o Trójcy Swiętej 1 Woielentu moga rozwazać jedynie c1, którzy, wyzbywszy sie pychy, zdecydowali sie na łagodność 1 pokorê, aby przyjać Boga jako swego nauczyciela ${ }^{9}$.

\section{Analiza listu}

Vistep otwiera osobliwy dialog, w któryn Augustyn wyraźa niezwykzo zaskoczenie listem członków rady miejokiej. Zwracal1 sle bowien do biskupa katollcklogo,jak gdyby byl1 chrześcijanam1: "Patr1 Augustino in Domino aeternam saluten. .... Optamus te, domine, in Deo et Christo elus per multos annos semper in clero tuo gaudoren ${ }^{10}$. Biskup pod wpływern lektury listu odniósł wrazenie jakoby rządoy Madaury przyjęl1 chrześcijaństwo, albo przynajmniej otworzyl1 sie na jego przyjecio. Od posłanca listu dowiedziaz sie jednak, zo trwall w swych "oganiskich przekonaniaoh ${ }^{11}$. Dlatego w formie pytań poddajo w watpliwośc szczerość pozdrowienia przesłanego mu przez mieszkaicóv Madaury, stwlerdzając zo, Jeśli pogante wymieñll w swym liscio linie Chrystusa nie wiorzac w niego, to wówozas zadrwili z Chrystusa

9 Eptstola $232,5, \operatorname{cSkL} 57,515$.

10 Taute 2, CSLL 57,511 .

11 Taito, CSLL 57,512: "comper1 nequaquam vos esse mutatos". 
$1 z$ biskupa ${ }^{12}$. Nie mógz jednak uwierzyć w to, że poganie potrafi11 szydzić z niego w l1śc1o, w któryo prosili go o ponoc. Wyaje s1e, ze sprawa jest jasna. Nadawcy listu byl1 jeszczo we pelni zdecydowanyml poganam1. Pisall list w tyin czasie, w którym chrześcijaństwo odnosizo wezelzie zwycięstwo. Hyszali prośbę do biskupa katolickiego. Uznali zatem, ze roztropniej będzie nie odsłaniać swotch przekonań, by ten sposób nie stawiać od razu biskupa przeciwkc soble. Dlatego zastosowall chrześcijańska formę pozdrowienia, która wówczas była " powszechnym uźyciu ${ }^{13}$.

Augustyn $w$ odpowiedzi na l1st nieszkańcón ladaury, uznaz, zo nadarza sie sposobność przodstawlenia mylssztakconyla poganom oryginalnosio1 religil chrześc1jańskiej. Lrótíl jego list do nich stanow1 zwięzł obronę imienta chrzescijaískiego 1 religil przeciw pogaustiru. Podkreśla, ze czuje sie wielce odporiedzialny wobec Boga za pogan, gdyby nadal trwali w odrzuceniu prawdy ${ }^{14}$. Viyjaśnta im, ze juz prorocy wykazal 1 welkość 1 wyzszość swego boga is stosunicu do pogańskich bóstw. Wskazywall na Boga, który kieruje według określonego planu. Wszystko odbywa siz tak, Jak to było pizenidziane w zamiarach bozych 1 przepowiedzlane przez proroków: "1ta omnino cuncta transount, ut transitura esse praodicta sunt"15. Klęsisa narodu żydowskiego, pojarienie si: Chrystusa, rozszerzanie się chrześcijaństua ${ }^{16}$, scinizay 1 herezje, a takzo konioo pogaństwa - wszystio to Juz byzo przewidziane 1 potwierdziło sip wełni ${ }^{17}$. Biskup podkreś1a, zo historia ta ma wyrazni wyıow. Poganie winni wyprowadzić z niej wniosek, to istnieje jeden prawdziwy 1 iszochmocny vóg, który kierujo wszystk1m, o któryu jest mowa w Bbll1, kreślqcej cały bieg dzlojów. Bóg jest czczony tylko w chrześcijaŕstwio, które dziéki niemu odniosło zwycięstro nad wszysteimi religlami czczącymi jedynio bozków. Augustyn kończy ten eragment zdaniem wywlerajłcym silno wra-

12 Tamio 1, CSEL 57,511 .

13 Por. Epistola 1171136.

14 Bpistola 232,3, CSLL 57,512 n: "Sciatis me, carissiai, cum inepfabll1 pro vobis trewore cordis haec dicere; novi enim, quanto gravioren et porniclosiorem causan sitis habituri apud Leum, 81 frustra vobis haec ulere".

15 TeLze 3, CSEL $57,513$.

16 Tasie: "omnlum gentium rider occupasse atque tenuisse".

17 Tasio: "praevisa, praedicta, scripta 6 unt omnia". 
zente:

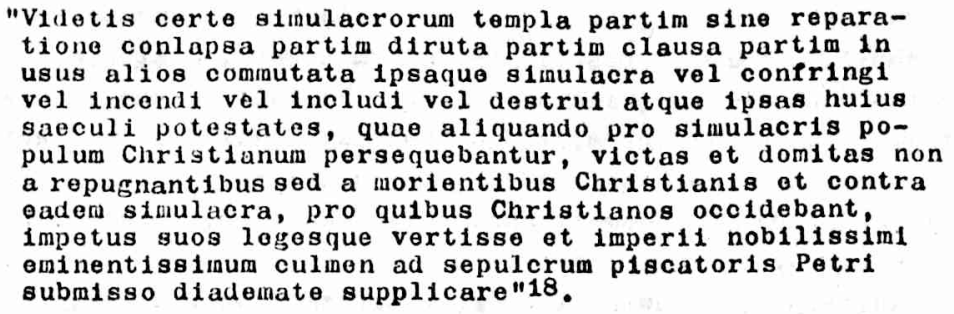

Augustyn ohcial najplerw wzbudzié podziw u pogan wobec Boga chrześcijan, który kieruje historla według ściśle określonego planu. Jeśli bowlen wypełn1ło się wszystko, o czym wspomniano wyżej, tak samo trzeba przyjąć, że spełni się także to, co jest napisane - przyszłósci, zwłaszcza o przyszłym sadzie. Totez biskup Hippony pragnie teraz wywoład w nich bojaźń przed sądem Boga:

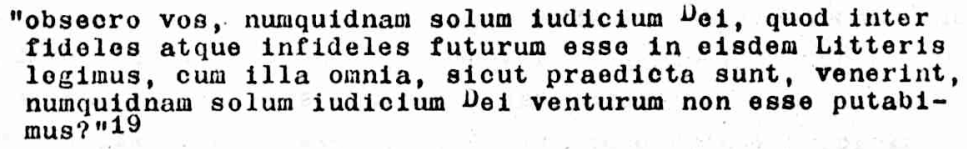

Natychmiast daje odpowiedź, ze sąd boży przyjdzie 1 wszyscy będa musioli zdać rozrachunek, takze poganie z Madaury, którzy maj z na ustach imie Chrystusa. Swojiz wypowiedz ujmujo w prozie rytmicznej, która dominowała w całym staroźytnym sposobio pisania, stosujace lzokolon:

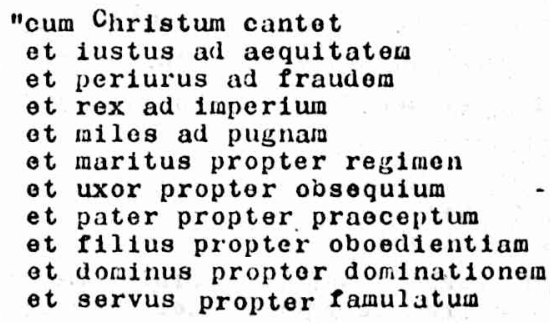




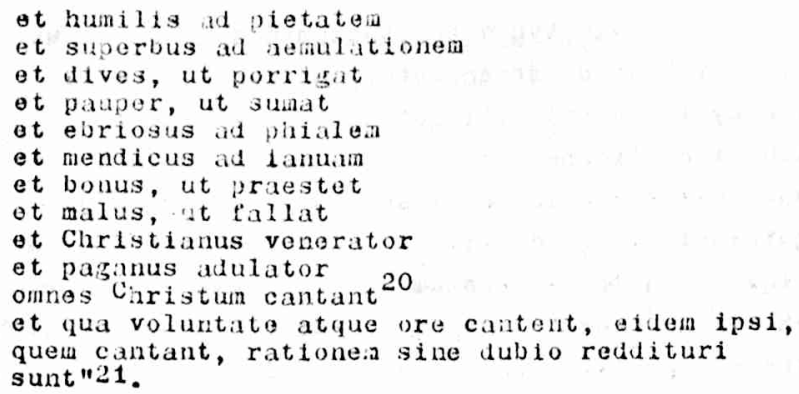

W ten sposób biskup Hippony stawia posan wobec podjęcia decyzj1, czy w obliczu zbliźaj zcego slę sadu claca nadal trwać w olrzuceniu Chrystusa.

Augustyn wzbudziwszy u inteszlsaúców Madaury podziw wobec Boga 1 uznanio woboc chrześcijan oraz bojaźn boż, usiłuje im przybliźý chrześcijański poglqd na Boga 1 nauk o zbawientu. Posługujac sie formulani neoplatońskimi, w ten oto sposób wyjaśnia zwiz̨źle tajeinniç chrześcijańskiogo Boga wiecznegro, niezraiennego i stwórcę oraz Jejo objawtenie sie w I'rójcy Sivig̨tej:

\footnotetext{
"Est quiddan invisibile, ex quo Creatore principio sunt omnia, quae videmus, summun, aeternum, incommuta ile et nulli offablle nisitantum sibl. Est quiddan, quo se ipsa summitas malostatis narrat ot praedicat, non inpar gignent1 atque narranti Verbuin, quo ille qui Verbum gignit, ostenditur. Est quaedam sanctitas onnium, quae sanctae fiunt, sanctificatrix, lpsius inconnutabilis Verbi, per quod narratur illud principium, et ipsius principid, quod part so vorbo narrat, insoparaisis ot indivisa communio. Quis autein noc totum, quod non dicendo dicere conatus sum et dicendo non dicere, quis hoc posste serenissina ot sincerissina nento contueri eoque contuitu beatitudinem ducere atque in id, quod intuetur, deficiens quodumodo se oblivisci et pergere in illud, culus visiono sibi vilis ost, quod est inmortalitate indui ot obtinere aetornam salutem, per quam me salutare dicnainini?"22
}

20 Por. K. Glasor, Klangetguren in dugustins. Brtefen, "Wiener Studien" 46/1328/ 19: n.; W. Parsons, A Study op the vocabulary and lunetinoric of the Letiers of Saint dugustine, rashington 1923,
253 .

21 Eptstola 232,4, CSEL $57,514$.

22 aunze 5, CSkL $57,514-515$. 
Sw. Augustyn w przytoczonym eragmenc10 unikał chrześcijańskiogo jezyka trynitarnego, stosujac pojęcia neoplatonskie, poniewaz odbiorcy listu byli filozoficznie przygotowani. Biskup wykorzystuje lch fllozoficzne 1 rotoryczne wyksztalcenie jako poinost, który ma mprowadzić w świat chrześc1janska wiarę. Mając wszechstronne przygotowanie mów1, do filozorów takim Jezykiem, jakim on obce 1m poglądy mogá lepiej zrozumieć. Augustyn swoim pogańskim rozmówcom chclal dać mozność objęcia myśla chrześcijaŕskich prawd. Dla podkroślenia niewyrażalnej w pełni fllozofleznej prawdy o Bogu zastosowal plgure retorycznz zwaną paradoksem/"quod non dicendo dicere conatus sum et dicendo non dicere"/, aby nie oszczędzić rządcom Madaury zaskakującego swoja treścia wniosku: "Quis hoc possit /obt1nere aeternam salutem - dodatek autora wynikajacy z kontekstu/, nis1 qui omnes suporbiae suae toros inanes peccata sua confitens complanaverit seque substraverit mitem atque humilem ad excipiendum doctorem Deum?"23

Przez to Augustyn zachęc1ł swolch korespondentów do wyzbycia sie pychy 1 uznania własnej grzesznośc1, której korzenie tkwia w dumnym wynoszeniu sį człowleka wobec Boga. H ten sposób dochodzi biskup do centrum chrzościjańskiego przepowladania, do orędzia o ukrzyżowanym Chrystusie, głównego zarzutu wyksztalconych pogan, unizonia się Syna Bożego Jezusa Chrystusa. Biskup podkreśla, zo w unizeniu Jezusa mamy najsilniojsza wskazówę na jedyna droge zbawienia, droge upokorzenia 1 bardzo silną zachętę, by rzeczyniście í́ć tá droga:

\footnotetext{
"Quoniam orgo a vanitate superbiae prius ad humilitatem deponend 1 sumus, ut inde surgentes solidam celsitudinem teneamus, non potuit nobis hoc tanto magnificentius quanto blandius inspirar1, ut nostra ferocitas non vi sed persuaslone sedaretur, nisl vorbum 1llud, per quod se angelis Indicat Veus Pator, quod virtus et sapientia olus est, quod corde humano visibilium rerun cupiditate caecato viderl non poterat, personam suam in homine agere atque ostendere dignaretur, ut wagis homo timeret extolil fastu nominis quars numil1ari exemplo De1"24.
}

23 Taraze, CSEL 57,515 .

24 Tauzo 6 , CSEL $57,515-516$. 
Wielkość Boga 1 moc ukrzyżowanego Jezusa uwldacznla się w wiolklej liczbio nawróceń. Tego faktu nie moga zaprzeczyć poganie w obliczu wielkiego rozszerzania sle chrześcijańgtwa. W unizeniu Chrystusa tkw1 jogo wielka sika:

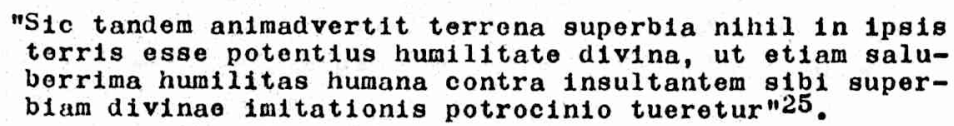

Biskup ukazuje swo1m korespondentom postać Chrystusa ponizonego jako boskiego przykładu ludzkiej pokory. Poganio winnt przyswolé soble tę chrześcijańska cnotę. Biskup kończy swój list wezwanier, aby obywatele Madaury nie zmarnowali sposobnośc1, jaka dał Im Bóg:

\footnotetext{
"Expergiscimini aliquando, fratres mei et parentes mei Madaurenses; hanc occasionem scribendi vobis Deus miht obtulit ... obsecro vos, si oum non inaniter in mea opistula nominastis, ut non inaniter vobis hoc scripserim. Si auten we inridere voluistis, timete illum, quem prius iudicatum inrisit superbus orbis terrarum et nunc ludicom sublectus expectat; erit onim testis affectus in vos cordis mei per hanc, quantum potui, paginam expressus, erit testis vobis in iudicio eius, qui credentes sibi ooneirmaturus est ot incredulos confusurus"26.
}

\section{Wnioski końcowe}

Uczony afrykański nakreśl1ł w swym lísclo historyozny rozwój religil, zaznaczajac, ze kończy sie zwyciesko walka z pogaństwem. W "De civitate Dex" te nowa rzeczywistość nazwie czasani chrześcijariskimi /terapora christiana/, podkreślając w ten sposób ostateozne ukształtowanie ole cywilizacji chrzešcijańskiej27. Pismo św. słuzy biskupow jako podstawa dla zrozumienia i interpretaoji lak-

25 Tanzo, 6, CSEL 57,516.

26 Tanzo $7, \operatorname{CSEL} 57,516-517$.

27 De civitate Dei I, 1, CC 47,1-2; Por. Spistolae 111, 21118 , $3,21, \operatorname{CSiL} 645,684$; Sermones: 81,$9 ; 105,6,8 ; 269,6,7$; PI 38 , 
tów w nim zapowledzianych, zarówno współczesnych autorow1 listu, jak 1 przysziych. W ten sposób dzieje ludzkości wyjaśnia w świetlo Objawienia Bozego. To samo zastosuje póznjej we civitate Dei", szczególnie w motywie dwóch państw, w których rozwiazzuje sie cała historia ludzkośct, podniesiona ponad płaszczyznę rozwazai hiotoryczno-filozoficznych, by być interpretowang w świetle Biblii. Inny motyw potwierdzony w liścle, to pokora/humflitas/chrzescijariska przecirstawiona pysze/superbia/. Humilitas wasciwa jest paristwu Bozemu /civitas De1/a a superbia - paristwu ziemskiemu/civitas terrena/. Lozdziaz 4 listu zapowiada ostatnie ksiggi "je civitate Ne1" poświęcone zagadnieniom eschatycznym. Widoczne jest tez podobieństwo shróconej historii chrześcijaristwa od poczz̨tiu do tryumPu, zawartej v tym liście do wielu stronz "De civitiato dei", w których autor szerzej omawia etapy rozwoju religil chrześcijańskiej 28. Hroszcie wezwanie do pogan z Madaury, zawarte w rozdz. 7 21stu, zachęcająoe tch do nawrócenia, stanowi pewne echo słowne, którym zwraca sie Augustyn do izymian w 29 rozdz. II kgizgi. "De civitate vei"29.

List ten pozwala poznać sposób pasterskiego działania Augustyna wobec wykształconych pogan. Biskup okazuje się przy tym dobrym psychologiem, który zna swego rozmówcé $i$ odpowiednio do tego kształtuje swoje wystopienia. z pomoca historii, której fakty ma przed oczyna, filozofii, której jezyk jest bardziej zrozumiały dla wyksztalconych pogan niz prosty jezyl biblid, ukazuje poganom istotę chrześcijansiliej nauki. Pragnie wzbudzić w nich zbawienny niopokój, który moze stac sié pomocny w dojéciu do wiary w Chrystusa.

\section{Ks. Augustyn Eokmann - Lublin}

\section{DE EPISTOLA S.AUGUSTINI AD PAGANOS MADAULENSES IIISSA /Argumentum/}

Auctor huius articuld CCXXXII epistolam sancti Auguetind prolixe et copiose exponit. Priom circumstantias ac tempus scribendac epistolae explicat, detnde argunentun eius ainutiose scrutatur, postromum varios conclusiones colligit. Lx epistola modus pastorails agendi episcopl tipponensis erga paganos liberalibus doctrinis

28 De c1vitate Le1 XVIII, 46-54, CC 48,643-656.

29 'lanze II, $29, \mathrm{CC} 47,63-65$. 
oxcultos oognosol potest. Auguatinus historiae, oulus racta bone Intolligobat, ot philosophiae, culus lingua doctis paganis $111 \mathrm{a}$ Sacrao scripturae notior orat, auxil10 nixus mag1stratibus Madau- rensibus doctrinam ohristianam exposuit. In opistola sua historicat evolutionem religionts prosooutis os atque viotricom pugnam oontra paganitatom einiri rationibus oonfirmavit. Madauronses hortatus est, ut Christ1 religlonem ampleoterentur. Terroris novissiml ludioli corte venturi, siout lam ootera de ohristiana roIIglono in Saora Soriptura praediota evenerunt, monuit, atque Trinitatis ot Inoarnationis mysterium leviter perstrinxit. 